\title{
The Simulation Research of the pollution level of ceramic insulator in air contamination environment
}

\author{
Song Gao ${ }^{1, a^{*}, \text { Lin Zhang }}{ }^{2}$, Zhicheng Zhou ${ }^{1}$, Fengbo Tao ${ }^{1}$, \\ Long Zhang ${ }^{2}$, Zhulin Yuan ${ }^{2}$ \\ ${ }^{1}$ Jiangsu Electric Power Company Research Institute , Nanjing 211103, China \\ ${ }^{2}$ Southeast University , Nanjing 210009, China \\ *hvgaosong@foxmail.com
}

\begin{abstract}
Keywords: Ceramic Insulator; Air particulate matter; ESDD and NSDD; Insulator surface contamination simulation

Abstract. Ceramic Insulator is an important part of the electric power equipment. When the deposition of pollutant in the air contamination environment is serious, the uniform distribution of voltage in the ceramic insulator bunch will be changed in the real working environment and leads to an accident. This paper use the $\mathrm{XWP}_{2}-160$ ceramic insulator as an example to do the simulation calculation of the deposition of pollutant on the surface of ceramic insulator in the natural with the method of computational fluid dynamics and the involvement of the deposition of pollutant's potency and the environmental condition. The comparison of the measured value and computing result shows that the computing result can reflect the level of deposition of pollutant on insulator in the real environment and to predict the ability of insulation of insulator.
\end{abstract}

\section{Introduction}

Ceramic insulator is a very important content of Transmission and distribution Equipment. It is usually connected by lots of elements. It is used on the High voltage transmission line to play the role of insulation and sustain. Insulator is exposed to the serious air environment for long time. They bear the electrical, mechanical, chemical influence and other different condition. Recently, the fog and haze is frequently happened in China, the contamination of environment is more and more serious; the deposition of pollutant such as the industrial dust, the agricultural chemical fertilizer and the acid rain, can change the uniform distribution of voltage in the insulator bunch. As a result, a majority of voltage focus on several insulators. High voltage will cause to the insulator ageing, the breakdown of insulator and other problems, which give rise to insulator invalid and power grid accidents.

This paper use the combination of simulation experiments and natural pollutant deposit experiment to research the level of pollutant deposition of $\mathrm{XWP}_{2}-160$ insulator, which with double umbrella structure and ceramic glaze semiconductor constitution, to acquire the insulation ability of insulator in the air contamination environment.

\section{The numerical simulation model of the contamination accumulation of porcelain insulator}

Based on the air pollutant concentration and meteorological information of two heavily polluted areas in Xuzhou City, the numerical simulation model of the contamination accumulation of porcelain insulator was built. Computational fluid dynamics (CFD) methods were adopted to simulated the process of contamination accumulation on ceramic insulators in the natural environment, the gas-phase field and the discrete particle field were treated respectively by a Eulerian method and a Lagrangian one.

Physical model. The section headings are in boldface capital and lowercase letters. Second level headings are typed as part of the succeeding paragraph (like the subsection heading of this paragraph). 


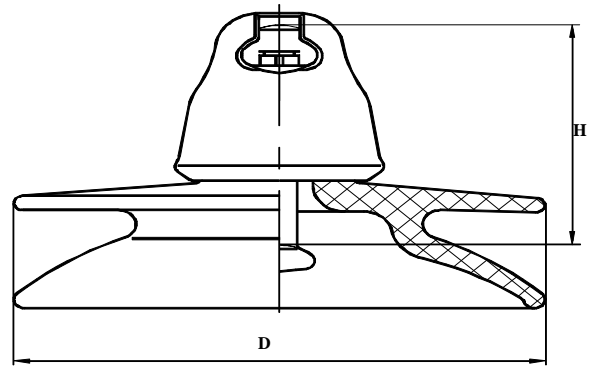

Fig.1 Structural schematic of XWP-160 porcelain insulator

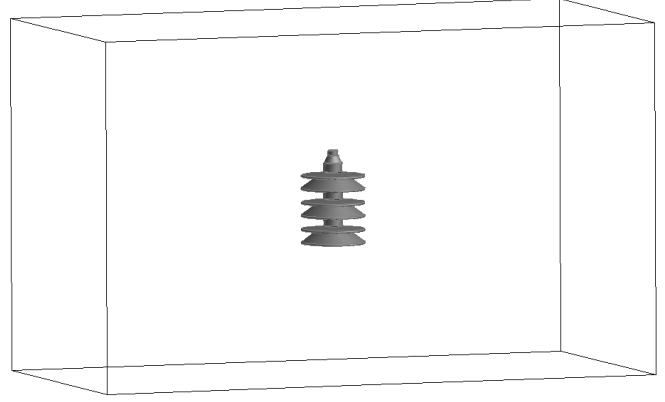

Fig.2 Calculation region of three XWP-160 porcelain insulators

The size of $\mathrm{XWP}_{2}-160$ porcelain insulator is shown in Fig. 1, structure height: $\mathrm{H}=155 \mathrm{~mm}$, nominal diameter: $\mathrm{D}=300 \mathrm{~mm}$. The model includes three insulators, and calculation region is shown in Fig. 2 The size of the calculation region is $2000 \mathrm{~mm} \times 1100 \mathrm{~mm} \times 1635 \mathrm{~mm}$ (length, width and height). The entrance face was set as velocity inlet, the exit face was set as outflow. The top and bottom surface were set as symmetry boundary, the insulator surface was set as no slip wall. Unstructured grid was used to mesh the calculation region.

Mathematical model of gas phase. Based on the characteristics of gas phase around the insulators, the gas phase is considered as three dimensional, steady, turbulent, and incompressible flow.

\section{Continuity equation.}

$$
\frac{\partial \mu_{i}}{\partial x_{i}}=0
$$

Momentum conservation equation.

$$
\frac{\partial u_{i}}{\partial t}+\frac{\partial}{\partial x_{i}}\left(u_{i} u_{j}\right)=-\frac{1}{\rho} \frac{\partial P}{\partial x_{i}}+\frac{\partial}{\partial x_{j}}\left(v \frac{\partial u_{i}}{\partial x_{j}}\right)
$$

$\mathrm{i}, \mathrm{j}=1,2,3, \rho$ is the fluid density, $\mathrm{v}$ is the fluid kinematic viscosity coefficient.

\section{RNG k- $\varepsilon$ equation.}

The velocity gradient of the airflow around the insulators is high, and phenomenon such as eddy and backflow are possible to occur at the back of insulators. To increase the computational accuracy of flow field, the RNG k- $\varepsilon$ turbulence model was adopted in the calculation.[1]

$$
\begin{aligned}
& \frac{\partial(\rho \varepsilon)}{\partial t}+\frac{\partial\left(\rho \varepsilon v_{i}\right)}{\partial x_{i}}=\frac{\partial}{\partial x_{j}}\left(\sigma_{\varepsilon} \mu_{e f f} \frac{\partial \varepsilon}{\partial x_{j}}\right)+\frac{C_{1}}{k} G_{k}-C_{2} \rho \frac{\varepsilon^{2}}{k} \\
& \frac{\partial(\rho k)}{\partial t}+\frac{\partial\left(\rho k v_{i}\right)}{\partial x_{i}}=\frac{\partial}{\partial x_{j}}\left(\sigma_{k} \mu_{e f f} \frac{\partial k}{\partial x_{j}}\right)+G_{k}+\rho \varepsilon
\end{aligned}
$$

$\mathrm{G}_{\mathrm{k}}$ is the generation item of tubulence energy $(\mathrm{k})$ caused by the average gradient, $\mathrm{C}_{1}$ and $\mathrm{C}_{2}$ are th e empirical coefficient, $\sigma_{\mathrm{k}}$ and $\sigma_{\varepsilon}$ are the Prandtl number of tubulence energy $\mathrm{k}$ and turbulent dissipat ion rate respectively, $\mu_{\mathrm{eff}}=\mu+\mu_{\mathrm{T}}$. 
Mathematical model of discrete particle motion. The motions of the contaminant particles are affected by gravity, drag force, and van der Waals force. The particles are simplified as uniform and hard spheres, and the interaction forces between particles are ignored, the particles are considered to be captured once they touch the surface of the insulators.[2]

The motion equation of discrete particles:

$\frac{d u_{p}}{d t}=F_{D}\left(u-u_{p}\right)+\frac{g_{x}\left(\rho_{p}-\rho\right)}{\rho_{p}}+F_{v}$

$F_{D}\left(u-u_{p}\right), \frac{g_{x}\left(\rho_{p}-\rho\right)}{\rho_{p}}$, and $F_{v}$ are the drag force, gravity, and van der Waals force respectively.

Drag force:

$F_{D}=\frac{18 \mu}{\rho_{p} d_{p}^{2}} \frac{C_{D} R_{e}}{24}$

$\mathrm{R}_{\mathrm{e}}$ is the Reynolds number of particles:

$R_{e}=\frac{\rho d_{p}\left|u_{p}-u\right|}{\mu}$

Van der Waals force:

$F_{v}(h)=A \frac{2}{3 r\left[(h / r)^{2}-1\right]^{2}}$

$\mathrm{A}$ is Hamaker number, $\mathrm{A}=2.0 \times 10-20,[3] \mathrm{r}$ is the radius of particles, $\mathrm{h}$ is thedistance between the center of particle and the surface of insulator.

Computational conditions.

Air pollutant concentration and meteorological information. The air pollutant concentration and meteorological information provided by the atmospheric pollutants diffusion numerical model are shown in table 1-3.

Table.1 Meteorological data of experimental site one from October 2014 to May 2015

\begin{tabular}{|c|c|c|c|c|}
\hline Date & $\begin{array}{c}\text { Temperature } \\
\left({ }^{\circ} \mathrm{C}\right)\end{array}$ & $\begin{array}{c}\text { Horizontal } \\
\text { velocity } \\
(\mathrm{m} / \mathrm{s})\end{array}$ & $\begin{array}{c}\text { Vertical } \\
\text { velocity } \\
(\mathrm{m} / \mathrm{s})\end{array}$ & $\begin{array}{c}\text { Wind } \\
\text { direction } \\
\left({ }^{\circ}\right)\end{array}$ \\
\hline Oct-Nov & 13.6 & 2.85 & 0.0006 & 152.4 \\
\hline Dec-Jan & 2.6 & 2.61 & -0.0016 & 185.8 \\
\hline Feb-Mar & 7.3 & 3.19 & 0.0012 & 165.9 \\
\hline Apr-May & 17.8 & 3.38 & 0.0017 & 156 \\
\hline
\end{tabular}

The experiment time was divided into four periods, the average data of every period are shown in the tables. In the experiment, the insulators were hung at the height of $10 \mathrm{~m}$, as is shown in table 1 , the vertical wind velocity is low at $10 \mathrm{~m}$, so the flow field of insulators is mainly affected by the horizontal wind. In the model, $0^{\circ}$ represents the north direction, $90^{\circ}$ represents east, $180^{\circ}$ represents south, $270^{\circ}$ represents west. According to the number and mass concentration of the particles in table 2 , the particles of $0.1-2.5 \mu \mathrm{m}$ play a major role in the contamination accumulation of insulators. Although the number concentration of the $2.5-10 \mu \mathrm{m}$ particles is low, due to the big size, particles in this range can affect the contamination accumulation obviously. The mass concentration of the 0-0.1 um particles is low, so their effects on the contamination accumulation is almost negligible. As is shown in table 2, the percentage of ESDD and NSDD can be obtained, the main elements of salt 
and dust were listed in table 3,in the table, OC is the black carbon, EC is the organic carbon, ASOIL is the soil particle, AOTHR are other dust elements except those listed in the table.

Table.2 Contaminant data of experimental site one from October 2014 to May 2015

\begin{tabular}{|c|c|c|c|c|c|c|c|c|}
\hline \multirow{2}{*}{$\begin{array}{c}\text { Date } \\
\text { (month) }\end{array}$} & \multicolumn{3}{|c|}{$\begin{array}{c}\text { Number concentration ( /c } \\
\mathrm{m} 3)\end{array}$} & \multicolumn{3}{c|}{$\begin{array}{c}\text { Mass concentration } \\
(\mu \mathrm{g} / \mathrm{m} 3)\end{array}$} & \multicolumn{2}{c|}{$\begin{array}{c}\text { Percentage } \\
(\%)\end{array}$} \\
\cline { 2 - 9 } & $\begin{array}{c}0-0.1 \mu \\
\mathrm{m}\end{array}$ & $\begin{array}{c}0.1-2.5 \\
\mu \mathrm{m}\end{array}$ & $\begin{array}{c}0.1-2.5 \\
\mu \mathrm{m}\end{array}$ & $\begin{array}{c}0-0.1 \\
\mu \mathrm{m}\end{array}$ & $\begin{array}{c}0.1-2.5 \\
\mu \mathrm{m}\end{array}$ & $\begin{array}{c}0.1-2.5 \\
\mu \mathrm{m}\end{array}$ & ESDD & NSDD \\
\hline Oct-Nov & 709.6 & 8265 & 1.89 & 0.455 & 75.6 & 20.3 & 0.411 & 0.589 \\
\hline Dec-Jan & 1051 & 9817 & 4.51 & 0.811 & 87.9 & 44.9 & 0.319 & 0.681 \\
\hline Feb-Mar & 1081 & 7608 & 3.27 & 1.178 & 71.9 & 32.6 & 0.392 & 0.608 \\
\hline Apr-May & 1041 & 6134 & 2.59 & 1.163 & 57.7 & 27 & 0.427 & 0.573 \\
\hline
\end{tabular}

Table.3 The main elements of salt and dust in the air

\begin{tabular}{|c|c|c|c|c|c|c|c|c|}
\hline salt & $\mathrm{Ca}^{2+}$ & $\mathrm{K}^{+}$ & $\mathrm{Mg}^{2+}$ & $\mathrm{NH}_{4}^{+}$ & $\mathrm{Na}^{+}$ & $\mathrm{SO}_{4}{ }^{2-}$ & $\mathrm{NO}_{3}^{-}$ & $\mathrm{Cl}^{-}$ \\
\hline dust & OC & EC & ASOIL & $\mathrm{Fe}_{2} \mathrm{O}_{3}$ & $\mathrm{Al}_{2} \mathrm{O}_{3}$ & $\mathrm{SiO}_{2}$ & $\mathrm{AOTHR}$ & \\
\hline
\end{tabular}

Computational conditions. The weekly average data were used as our computational conditions. The density and viscosity of the air were obtained based on the temperature, the horizontal and vertical wind speed were used as the inlet conditions of the model, the manometer pressure of the outlet was 0 , the adiabatic and non-slip boundary conditions were used in the model. The size distribution of the three particle ranges presented normal distribution respectively, and the peak particle sizes of the three normal distribution curves are $0.03 \mu \mathrm{m}, 0.3 \mu \mathrm{m}, 6 \mu \mathrm{m}$, so the three sizes were used as the average particle sizes. The densities of the particles were calculated with number concentration, mass concentration, and average particle size. The inlet velocity of the particles was consistent with that of the air.

The solution of the mathematical model.The calculation of discrete phase was based on the Lagrange method. The shapes of the contaminant particles were simplified as spheres, the gas phase datas of the grids which the particles were in were read and used to calculate the forces on particles, then the accelerated speeds, speeds, and locations of the particles were obtained, and the particle trajectories were calculated at each time step. The number of the sampling particles was obtained based on the number concentration of particles and the model dimension. The Monte Carlo method was used to determine the ratio between the sampling particle number and the real particle number. Considering the capacity of the computer, in the numerical calculation, the computing time was set as one minute to replace one week in the experiment, and the computation results were modified by the time correction factor.

\section{Research results and analysis}

Analysis of the surrounding flow field and the contamination accumulation position of the insultors. The contours of the average velocity of the second and fourth experiment period are shown in Fig.3. From the two figures, it can be found that there are high speed regions above the small umbrella skirt and below the big umbrella skirt, which can cause the acceleration of contamination accumulation. The velocity of the boundary layer on the surface of the insultors is low, which can cause the conglutination of contaminant particles on the insultors. Under the wind speed of $2.61 \mathrm{~m} / \mathrm{s}$, the air velocity decreases significantly near the insultors. However, when the wind speed is $3.38 \mathrm{~m} / \mathrm{s}$, 
the rate of velocity decreasing is relatively low, which causes high velocity distribution around the insultors and rapid contamination accumulation.

The velocity vectors of the gas-phase flow fields under two wind speeds are shown in Fig.4. Because of the upward sloping shape of the umbrella skirts, the air near the insultors flows upwards, so under the effect of drag force, the contaminant particles can be carried by the upward airflow to the inner regions of the umbrella skirts. What's more, as is shown in the two figures, at the edge of every umbrella skirt, the airflow was divided into two streams: the upward stream and the downward stream. Between the two streams, the direction of the airflow is towards the edge of the umbrella skirts, so the rate of contamination accumulation at the edge of the umbrella skirt can be rapid.

To study the contamination accumulation position on the insultors, three surfaces of the porcelain insultor were selected: the top surface of the small umbrella skirt, the top surface of the big umbrella skirt and the bottom surface. The contamination deposit density contours of the three surfaces are shown in Fig. 3 to 5, and the figures were obtained under the wind speed of $2.61 \mathrm{~m} / \mathrm{s}$. From table 1, the average wind direction of the second experiment period is $185.8^{\circ}$. As is shown in the three figures, on the top surface, most of the contamination were distributed on the windward side and the distribution range is from $60^{\circ}$ to $240^{\circ}$. On the bottom surface, most of the contamination were distributed on the leeside and the distribution range is from $270^{\circ}$ to $30^{\circ}$. From Fig.5, on the top surface of the small umbrella skirt, most contamination were distributed on the inner region and the edge of the umbrella skirt, which is caused by the upward airflow and the divided streams. From Fig.6, on the top surface of the big umbrella skirt, most contamination were distributed on the edge of the umbrella skirt, and there are little contamination accumulated on the the inner region. As is shown in Fig.3, the air velocity above the big umbrella skirt is low, so the contaminant particles above the big umbrella skirt deposited on the edge of the umbrella skirt under gravity and were unable to be carried to the inner region. From Fig.7, on the bottom surface, most contamination were distributed on the inner region, which is caused by the upward airflow.
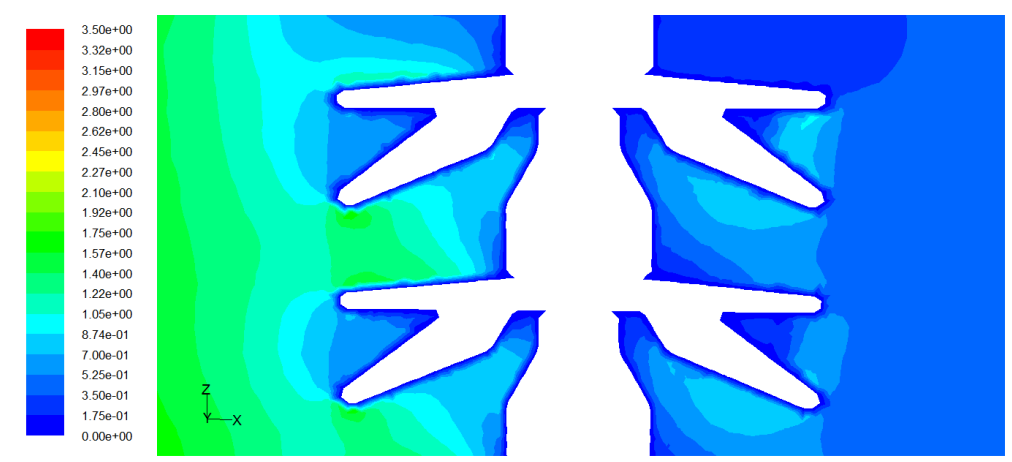

(a) $\mathrm{v}=2.61 \mathrm{~m} / \mathrm{s}$
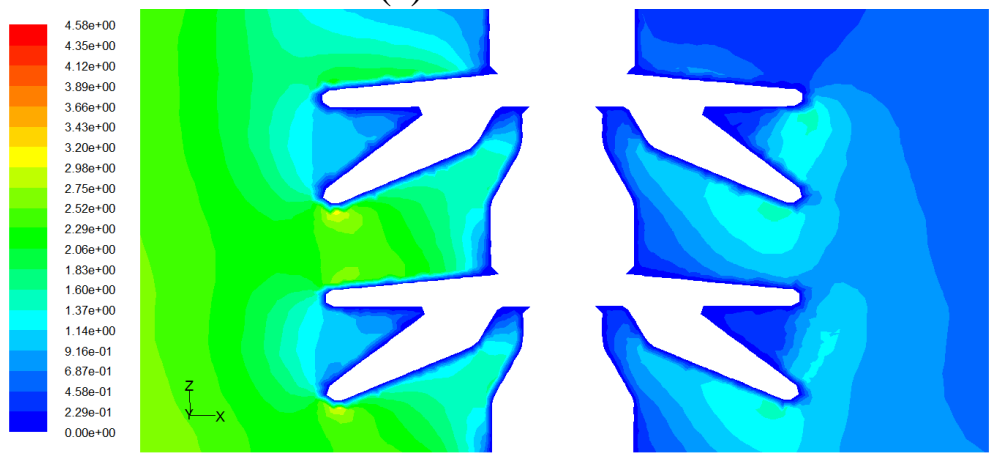

(b) $v=3.38 \mathrm{~m} / \mathrm{s}$

Fig.3 Velocity contour of the gas-phase flow field 

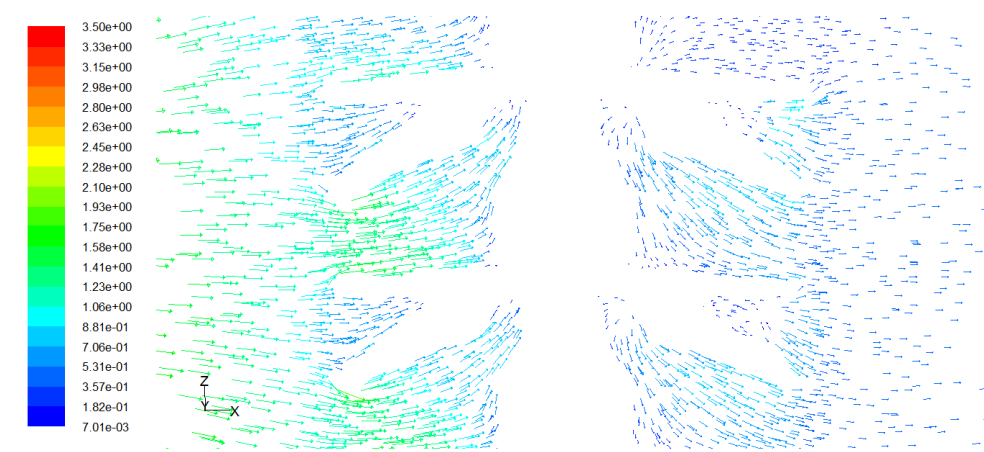

(a) $\mathrm{v}=2.61 \mathrm{~m} / \mathrm{s}$
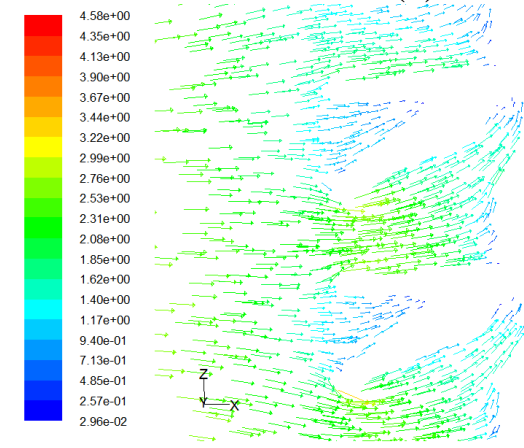

(b) $\mathrm{v}=3.38 \mathrm{~m} / \mathrm{s}$

Fig.4 Velocity vector of the gas-phase flow field

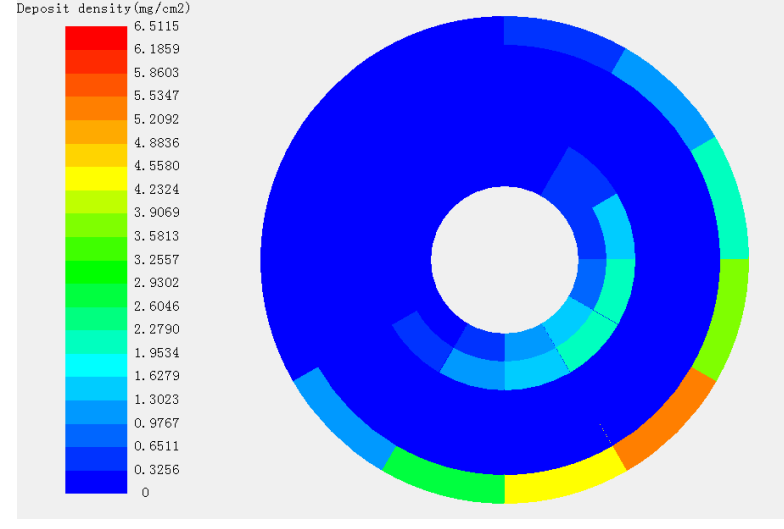

Fig.5 Contamination deposit density contour of the top surface of the small umbrella skirt

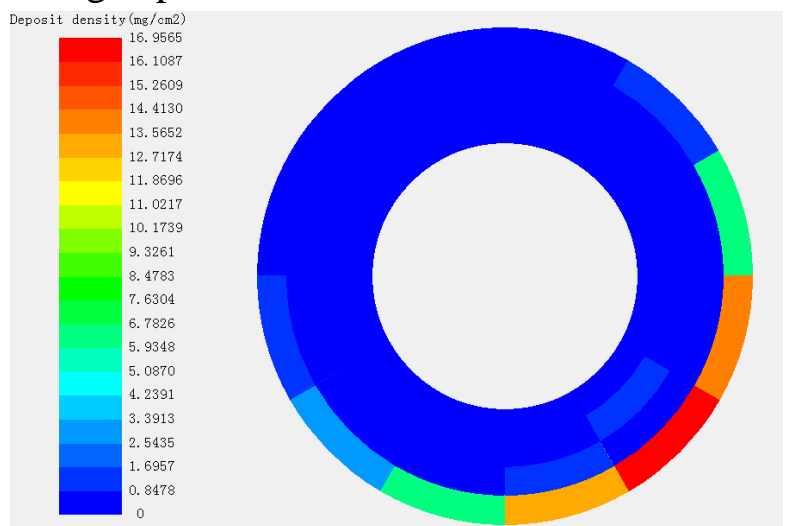

Fig.6 Contamination deposit density contour of the top surface of the big umbrella skirt

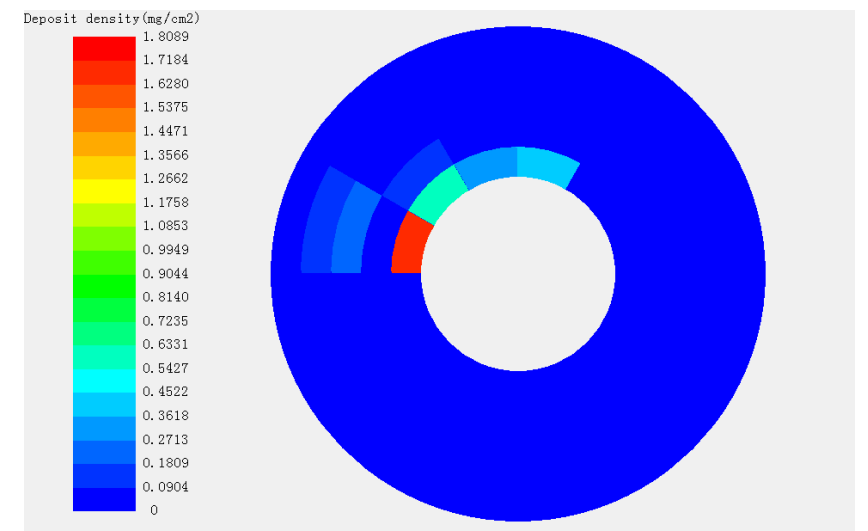

Fig.7 Contamination deposit density contour of the bottom surface

Experimental results. Two heavily polluted areas in Xuzhou City were selected as our experiment sites, the first site was near a railway and the second one was close to an cement plant. Twelve 
insulators were hung at every site at the beginning of the experiment, and three of them were picked off every two months. To guarantee the accuracy and reliability of the experimental results, the ESDD and NSDD of the three insulators were averaged. The experiment time was from October 2014 to June 2015. Salt density measuring instrument and electronic scales were used to measure the ESDD and NSDD respectively.

The insultors were tested on the basis of top and bottom surface. The measurement results of the two sites were shown in Fig.8and Fig.9, as is shown in the two figures, the ESDD and NSDD of the insultors increased at first and then decreased during the experiment time, which is consistent with the change of particle concentration in table 2 .

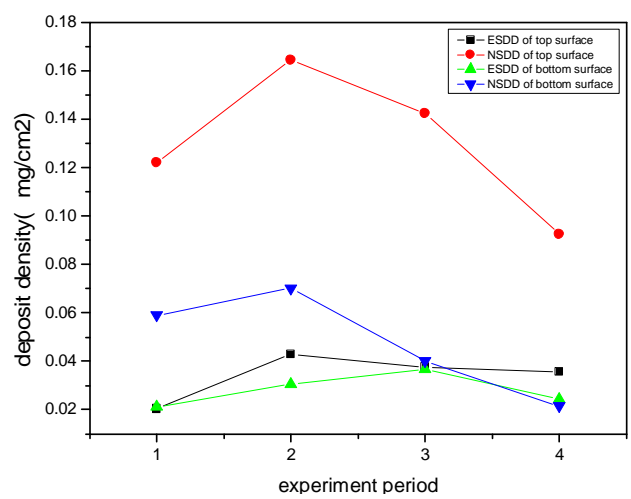

Fig.8 Experimental results of experiment site No.1

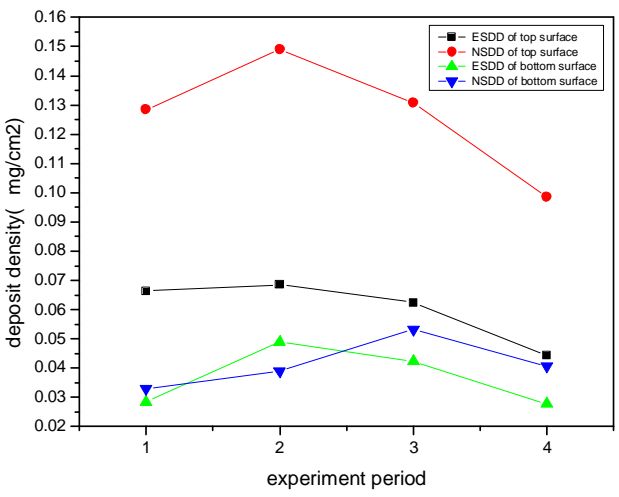

Fig.9 Experimental results of experiment site No.2

\section{Comparison of numerical simulation results with experimental results.}

The analysis of the results of top surface. In our study, the numerical simulation results were used as the original results without regard to the effect of rain, the difference values between the original results and the experimental results were used as the amount of contaminantion washed by the rain. The ratios of the difference values to the original results are the removal rates of the rain, which were used to reflect the washing effect of the rain. The average removal rates of ESDD are $89.6 \%$ and $81.4 \%$, the average removal rates of NSDD are $74.2 \%$ and $75.9 \%$. The results show that the average removal rates of ESDD are bigger than that of the NSDD, and for the top surface, the washing effect of the rain on ESDD and NSDD are obvious.

The numerical simulation results were modified with the average removal rate. As can be seen from Fig.10, the modified numerical simulation results increased firstly and then decreased, which is consistent with the experiment results. The average relative error of ESDD were $22.5 \%$ and $19.6 \%$, the average relative error of NSDD were $16.1 \%$ and $27.7 \%$, which can meet the requirements of the accuracy of measurement.

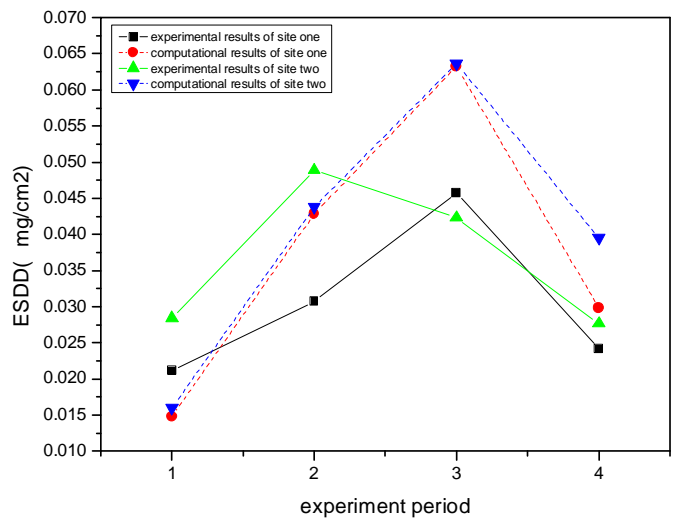

(a) experiment site No.1

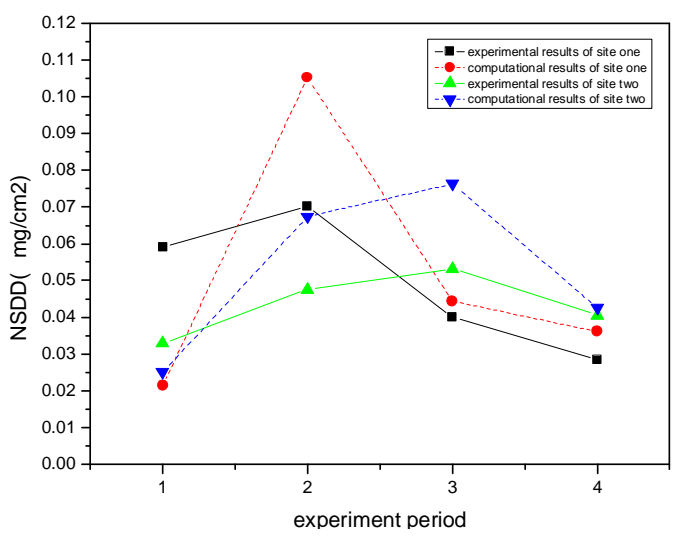

(b) experiment site No.2

Fig.10 Comparison of modified numerical simulation results with experiment results of the top surface 
The analysis of the results of bottom surface. As is shown in Fig.11, for the bottom surface of the insulators, the differences between experimental results and computational results are not obvious, which can be explained by the fact that the rain washing effect on the top surface is much greater than that on the bottom surface. The basic trend of computational results corresponds with the experimental results, and the average relative error of ESDD were $32.9 \%$ and $36.8 \%$, the average relative error of NSDD were $37.8 \%$ and $28.5 \%$. The average relative errors are relatively high, which can be caused by the small amount of rain falls on the bottom surface and other influence factors. Considering the complexity of various influence factors in the nature environment, it is difficult to take all the factors into account, so the computational results can meet the requirements of the accuracy of measurement.

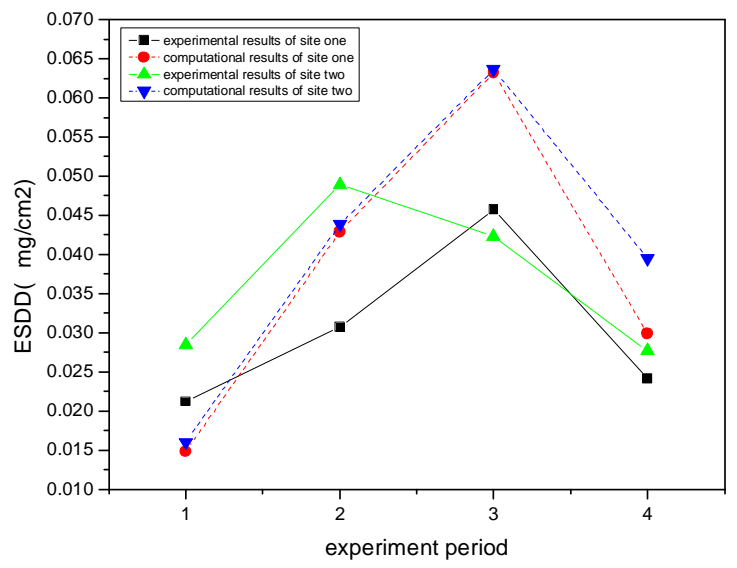

(a) experiment site No.1

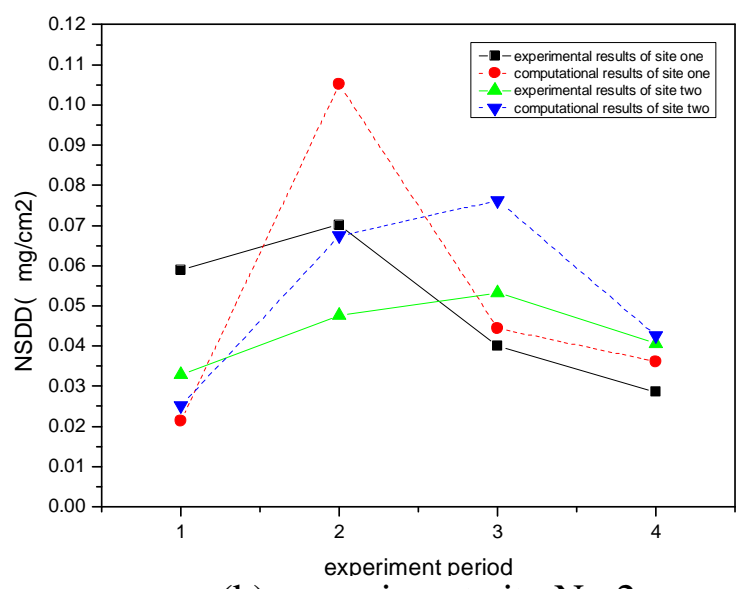

(b) experiment site No.2

Fig.11 Comparison of numerical simulation results with experiment results of the bottom surface

\section{Conclusions}

The deposition of air pollutants can change the voltage distribution of the ceramic insulator strings, which may cause the deterioration of the insulators and the insulation failure.

In the nature environment, the flow field of insulators is mainly influenced by the horizontal wind, the $0.1-2.5 \mu \mathrm{m}$ particles play a major role in the contamination accumulation of the insulators.

There are high speed regions above the small umbrella skirt and below the big umbrella skirt, which can cause the acceleration of contamination accumulation. The velocity boundary layer can cause the conglutination of contaminant particles. The high wind speed results in rapid contamination accumulation.

On the top surface, most of the contamination were distributed on the windward side. On the bottom surface, most of the contamination were distributed on the leeside. Because of the upward airflow and the divided streams, most of the contamination were distributed on the inner region and the edge of the umbrella skirt.

The washing effect of the rain is obvious for the top surface, and the average removal rate of ESDD is bigger than that of the NSDD. The numerical simulation results were modified with the average removal rate. By comparing the numerical simulation results with the experiment results, it is found that the numerical simulation model can reflect the variation trend of contamination accumulation effectively and help to evaluate the insulating property of porcelain insulator.

\section{References}

[1] X.L.Jiang, H.B.Li, Application of Computational Fluid Dynamics to Analysis of Contamination Depositing Characteristics of Insulators, High. Volt. Eng., 36(2010),329-334.

[2] H.Z.Li, J.Y.Lai, Q.Lei, Collision and Adsorption of Contamination Particles on the Surface of Electrical Insulator, High. Volt. Eng., 38(2012)2596-2602. 
International Forum on Energy, Environment Science and Materials (IFEESM 2015)

[3] W.C.Tian, J.Y.Jia, G.Y.Chen, Digital density in Hamaker micro continuum medium principle and Hamaker constant, Chin. J. of Comput. Phys., 7(2001) 120-122. 